\title{
Late Presentation at Primary Diagnosis of Breast Cancer: Patients' Personality Characteristics and Attitudes
}

\author{
Thomas Kolben $^{\mathrm{a}}$ Susanne Beyer ${ }^{\mathrm{a}}$ Sanaz Ghasemi ${ }^{\mathrm{a}}$ Kerstin Hermelink ${ }^{\mathrm{a}}$ \\ Sarah Meister $^{a} \quad$ Tom Degenhardt $^{a} \quad$ Isabelle Himsl $^{\mathrm{b}} \quad$ Franz Edler von Koch $^{\mathrm{b}}$ \\ Theresa M. Kolben ${ }^{a}$ Rachel Wuerstlein ${ }^{a}$ Sven Mahner ${ }^{a}$ Nadia Harbeck $^{a}$ \\ Anna Hester ${ }^{a}$ \\ ${ }^{a}$ Department of Obstetrics and Gynecology, Breast Center and CCC LMU University Hospital, LMU Munich, \\ Munich, Germany; ${ }^{b}$ Department of Obstetrics and Gynecology, Klinikum Dritter Orden, Munich, Germany
}

\section{Keywords \\ Breast cancer - Delayed presentation - Exulceration · \\ Psychological characterization · Personal characteristics}

\begin{abstract}
Introduction: Breast cancer $(\mathrm{BC})$ is the most common cancer in women worldwide. Despite screening and information efforts, about $10 \%$ of patients present with tumor size T3 or T4 at primary diagnosis. Late presentation is associated with more advanced tumor stage and consecutively with worse survival rates. Objective: This study aimed to evaluate whether patients with a late presentation at primary BC diagnosis differ in their personality from those with early diagnosis. Methods: In this bicentric, observational study, personality traits, positive and negative affectivity, anxiety, spirituality, illness beliefs, and sociodemographic characteristics were assessed in $\mathrm{BC}$ patients who presented with T-stages 3 or 4 (late presenters) and T-stages 1 or 2 (controls) at initial diagnosis. Results: Forty patients (20 controls, 20 late presenters) were interviewed. "Late presenters" perceived their disease as long lasting and had significantly more "positive affectivity" in the current trait. Although no significant associations were found, there was a trend for late presenters to have higher education levels, less spiritual longing, less accurate explanation of their illness, less anxiety in the trait
\end{abstract}

scale, and more conscientiousness than the controls. Conclusion: As patients with late presentation for BC differ in specific psychological and sociodemographic characteristics from patients with early $B C$, the findings of this pilot project warrant additional investigations to identify further specific characteristics and motivations. Identifying patients at risk for late presentation and encouraging them to accept an earlier diagnosis could help to improve their therapy and, finally, their outcome.

(c) 2020 S. Karger AG, Basel

\section{Introduction}

Worldwide, breast cancer (BC) is the most common cancer in women and the most common reason for cancer-related deaths [1]. Known prognostic factors in BC predicting patient outcome are lymph node status, histologic grade and subtype, as well as tumor size [2].

Tumor burden at presentation is a key factor for outcome. According to the UICC staging system, 5-year relative survival rates for patients with stage 1 or 2 at presentation range from 95 to $70 \%$. Five-year survival rates for

T.K. and S.B. contributed equally to this work. 
patients presenting with stage 3 (locally advanced and/or highly nodal positive) and stage 4 (metastatic BC) range from 52 to $18 \%$ [3]. Using multimodal tumor therapy, it is possible to extend the 5 -year survival rate for patients with stage 4 disease up to $41 \%$, which is still poor compared to those with earlier disease stages $[4,5]$. These figures show that it is of utmost importance to diagnose BC as early as possible. Most patients in the western world are diagnosed at an early stage due to $\mathrm{BC}$ screening programs $[6,7]$. Nevertheless, there are around $10 \%$ of patients who present with stage 3 and 4 , including locally advanced BC $[3,7-9]$. Late presentation of patients with $B C$ is associated with shorter survival [10]. There is strong evidence for an association of late presentation with older age, whereas associations with socioeconomic status and ethnicity could not unequivocally be demonstrated [10].

The understanding of the relative risk of developing $\mathrm{BC}$, of the associated risk factors, and of the diversity of potential symptoms of BC seems to be limited in women of all ages. However, older women (65 years and older) have a lower perception of their personal risk of developing the disease and are less able to identify BC symptoms or risk factors [11]. In addition, negative beliefs about the disease and its treatment are more common among this group than among younger women. Such believes include concerns about disability, disfigurement, and adverse economic consequences [12].

Another factor leading to a delay in primary diagnosis seems to be a reluctance of these women to bother their general practitioner. Burgess et al. [13] further described a higher tendency among them not to express explicit fears and to be hesitant because of fearing the consequences of diagnosis and treatment of BC. Bish et al. [14] tried to build a theoretical model to explain late presentation based on self-regulation theory, the theory of planned behavior and implementation intentions. That model includes stages of symptom appraisal, attitudes towards help-seeking, and translating intentions into behavior.

In a retrospective study assessing sociodemographic characteristics, medical history, and psychological issues in $67 \mathrm{BC}$ patients, younger ( $\leq 40$ years) and older $(\geq 70$ years) age, use of alternative medicine, and psychiatric comorbidities were associated with locally advanced BC at primary diagnosis [15].

An overview of the current literature shows that there are factors that are associated with late presentation, such as older age, special health beliefs, and fears. But there has not yet been any investigation about the personality of women with locally advanced $\mathrm{BC}$ at presentation. To our knowledge, data regarding late presentation and personality characteristics in other cancer subtypes are missing as well. Due to these findings, the aim of this study was to determine differences of personality traits between patients who consult a physician only after symptoms of BC have persisted for an extended period of time (late presenters [LP]) and those who promptly seek medical help. Therefore, LP were defined by T-stage of T3 or T4. Their tumors were definitely to be noticed by the patients themselves earlier, especially in locally exulcerated cases. We further compared positive and negative affectivity, anxiety, spirituality, and illness beliefs of these patient groups. We defined "no difference in regard to personality characteristics" between control (C) group and LP as the null hypothesis. An alternative hypothesis was defined as "difference in regard to personality characteristics" between C group and LP. Knowledge about characteristics of women who are at risk of delay in seeking medical help for BC may help to tailor information targeting this patient population and to improve treatment options by detection of the disease at an earlier stage.

\section{Patients and Methods}

\section{Patient Characteristics}

In this bicentric study, 20 patients with locally advanced BC (T3 or T4) who presented at the Breast Center of the University of Munich (LMU) and the clinic "Dritter Orden" Munich between August 2013 and July 2017 were enrolled. Patients with histopathologically confirmed BC and locally advanced tumors (T3 or T4, particularly locally exulcerated and definitely palpable) at initial diagnosis were included. Thirteen of 20 patients presented with an ulcerated tumor. The tumor size, especially exulceration, was selected as inclusion criterion, since this allowed to identify patients who most probably had knowledge of the tumor at least for several months before presentation. Patients had to be $\geq 18$ years old, and informed consent was obtained from all individual participants included in the study.

A cohort of 20 patients with T-stage $\mathrm{T} 1$ or $\mathrm{T} 2$ at primary diagnosis and matched in age (+/ -5 years) to each of the patients with late presentation was recruited as a $\mathrm{C}$ group. The target of $40 \mathrm{pa}-$ tients (20 LP and $20 \mathrm{C}$ ) was determined in advance after estimating the occurrence of LP in our center respecting the low incidence of advanced tumors.

Exclusion criteria were inadequate German language knowledge, evidence of psychosis, and history of cancer other than basalcell carcinoma or dysplasia of the cervix.

Patients were recruited during the in-patient stay before surgery and after the consultation hours in the participating hospitals. This date of recruiting was selected as in this setting, enough time for disclosure and interview was guaranteed. All patients with T3 or T4 were asked for participation, no one refused to participate. After achieving the targeted number of 20 , the recruitment was closed. The same procedure was applied for the $\mathrm{C}$ group.

\section{Ethics Approval}

The participation in the study was not associated with any risk, disadvantage, or stress. Patient data were anonymized. The study was approved by the LMU ethics committee (reference number 322-13) and was conducted in accordance with the Declaration of Helsinki.

\section{Statistics}

All statistical analyses were performed by SPSS, version 23.0 (released 2015; IBM SPSS Statistics for Windows, IBM Corp., Armonk, NY, USA). To compare the characteristics and attitudes of the patient 
Table 1. Sociodemographic data in the late presenters and controls

\begin{tabular}{lcccc}
\hline & Late presenters & Controls & $p$ value & Test statistics \\
\hline Mean age (SD), years & $66(9.62)$ & $65.3(10.17)$ & 0.824 & $\mathrm{~T}=0.224$ \\
Mean number of children (SD) & $1.4(1.14)$ & $1.35(1.26)$ & 0.896 & $\mathrm{~T}=0.131$ \\
Educational level, $n$ (\%) & & & 0.840 & $\mathrm{~T}=0.206$ \\
$\quad$ Secondary school/lower & $5(25)$ & $7(35)$ & & \\
$\quad$ Higher than secondary school & $15(75)$ & $13(65)$ & & \\
Religion, $n$ (\%) & $3(15)$ & $5(25)$ & & $\mathrm{T}=0.377$ \\
$\quad$ No religion & $17(85)$ & $15(75)$ & & \\
$\quad$ Any religion (christian/muslim) & $2(10)$ & $0(0)$ & & \\
Relationship status, $n$ (\%) & $11(55)$ & $9(45)$ & & \\
$\quad$ Single & $1(5)$ & $9(45)$ & & \\
$\quad$ Married & $6(30)$ & $2(10)$ & & \\
$\quad$ Divorced & & & \\
$\quad$ Widowed & & & & \\
\hline
\end{tabular}

groups, $t$ tests or nonparametric testing (Mann-Whitney U test) were used depending on whether the data were normally distributed. For statistical significance, $p$ had to be $<0.05$. Due to the low number of patients, we also report trends detected in the analysis.

\section{Assessments}

This study was designed as a cross-sectional, observational, bicentric study. Between August 2013 and July 2017, patients who matched the inclusion criteria were assessed with different questionnaires between initial diagnosis and surgery. Five validated questionnaires were used, and patients' sociodemographic background was assessed. In order to collect information about patients' characteristics and personalities, the questionnaires asked for positive and negative feelings, personal assumptions regarding the illness, current and habitual feelings, personality factors (openness to experience, conscientiousness, extraversion, agreeableness, neuroticism), spiritual and religious engagement, education, symptoms, relationship to doctors, and attempts to explain.

Sociodemographic Questionnaire

A questionnaire regarding sociodemographic data, such as age, place of residence, nationality, religion, family, education, other diseases, symptoms, date and reason for first medical presentation, experience with cancer, and contact to alternative medicine, was developed for this study.

Positive and Negative Affect Schedule

Negative and positive affectivity in the current trial was assessed by the Positive and Negative Affect Schedule (PANAS) on 2 scales. Twenty feelings, described by 10 adjectives for the positive and 10 adjectives for the negative affect scale, were selected by Krohne et al. [16], such as active and irritable, proud and afraid, or strong and nervous. Patients were asked for the intensity of their feelings regarding these items and should relate them to a scale between 1 (not at all) and 5 (very much). Points were given in correlation to the intensity scale. For each scale (positive or negative affect), the points were summarized in the end and varied between 10 and $50[16,17]$.

Illness Perception Questionnaire-R

The Illness Perception Questionnaire-R (IPQ-R) aims to evaluate patients' personal assumptions and suppositions regarding the illness. The patients were asked for 14 current symptoms (e.g., pain, dyspnea, nausea, and others) and if they suspected these symptoms were associated with the illness. Furthermore, the pa- tients were asked to estimate the time to a response to the treatment and the controlling of the treatment, to estimate consequences, personal controlling, coherence, cyclic appearance, emotional representation, and causes of their illness. The estimations were scaled into 5 groups between "not at all" and "completely." For each scale (time to response, consequences, etc.), the points varied from 5 ("not at all") to maximally 15 points ("completely") $[18,19]$.

State-Trait Anxiety Inventory

The State-Trait Anxiety Inventory (STAI) consists of 20 questions measuring current anxiety (= "state anxiety"; e.g., nervous, relaxed and happy) and 20 questions assessing the persistent tendency to experience anxiety (= "trait anxiety"; e.g., calm, happy and secure) [20, 21]. Each scale contains positive and negative items. Patients have to choose between 4 intensities for each item. Points differ between 20 and 80; higher scores are related to greater anxiety. The method tries to differentiate between current and habitual anxiety.

NEO Five-Factor Inventory

The NEO Five-Factor Inventory (NEO-FFI), a short-version of the NEO-PI-R, consists of 60 items, which measure the personality traits openness to experience, conscientiousness, extraversion, agreeableness, and neuroticism [22]. Twelve questions for each personality trait exist and can be scaled between 0 (e.g., no openness for experience) and 4 (e.g., strong openness to experience). The result is the mean and can vary between 0 and 4 .

Spiritual and Religious Attitudes in Dealing with Illness-15

The Spiritual and Religious Attitudes in Dealing with Illness (SPREUK-15) questionnaires analyze the individual spiritual involvement. In 15 questions, the 3 scales desire for spirituality or access to spirituality, trust in a higher power, and reflection are questioned. For each item, 5 questions exist that can vary between 0 (no spiritual and religious attitudes) and 4 (strong spiritual and religious attitudes). Finally, the calculated value ranges between 0 and $100[23,24]$.

\section{Results}

\section{Sociodemographic Data (Table 1)}

A total of 20 patients each were included in the LP and in the $\mathrm{C}$ groups. The mean age was 65.5 years for 
Table 2. Questionnaire items with differences and significances between late presenters and controls

\begin{tabular}{|c|c|c|c|c|}
\hline & $\begin{array}{l}\text { Late presenters, } \\
\text { mean (SD) }\end{array}$ & $\begin{array}{l}\text { Controls, } \\
\text { mean (SD) }\end{array}$ & $p$ value & $\begin{array}{l}\text { Test statistics, } \\
\mathrm{T} / \mathrm{Z}\end{array}$ \\
\hline \multicolumn{5}{|l|}{ PANAS } \\
\hline Positive affect $\alpha=0.843^{*}$ & $37.10(5.07)$ & $32.00(7.78)$ & 0.019 & $\mathrm{~T}=2.46$ \\
\hline Negative affect $\alpha=0.841^{*}$ & $18.05(7.70)$ & $19.85(7.35)$ & 0.314 & $Z=-1.03$ \\
\hline \multicolumn{5}{|l|}{ IPQ-R $\alpha=0.651$} \\
\hline Timeline & $14.80(4.89)$ & $12.00(4.72)$ & 0.038 & $Z=-2.08$ \\
\hline Consequences & $13.70(4.18)$ & $13.85(4.85)$ & 0.917 & $\mathrm{~T}=-0.11$ \\
\hline Personal control & $15.60(2.92)$ & $14.30(3.98)$ & 0.247 & $\mathrm{~T}=1.18$ \\
\hline Control by treatment & $16.40(2.92)$ & $16.70(1.72)$ & 0.820 & $\mathrm{Z}=-0.23$ \\
\hline Coherence & $14.20(5.79)$ & $16.3(3.77)$ & 0.182 & $\mathrm{~T}=-1.36$ \\
\hline Appearance & $9.60(3.76)$ & $9.30(3.99)$ & 0.808 & $\mathrm{~T}=0.25$ \\
\hline Emotion & $14.65(6.61)$ & $17.75(4.89)$ & 0.100 & $\mathrm{~T}=-1.69$ \\
\hline \multicolumn{5}{|l|}{ STAI $\alpha=0.742$} \\
\hline State & $49.05(17.30)$ & $50.70(13.26)$ & 0.737 & $\mathrm{~T}=-0.34$ \\
\hline Trait & $34.55(12.19)$ & $37.70(10.23)$ & 0.174 & $\mathrm{Z}=-1.37$ \\
\hline \multicolumn{5}{|l|}{ NEO-FFI $\alpha=0.617$} \\
\hline Neuroticism & $1.50(0.99)$ & $1.51(0.72)$ & 0.978 & $\mathrm{~T}=-0.03$ \\
\hline Extraversion & $2.16(0.55)$ & $2.35(0.68)$ & 0.431 & $\mathrm{~T}=-0.94$ \\
\hline Openness to experience & $2.32(0.59)$ & $2.39(0.46)$ & 0.668 & $\mathrm{~T}=-0.43$ \\
\hline Agreeableness & $2.85(0.42)$ & $2.96(0.43)$ & 0.353 & $\mathrm{~T}=-0.80$ \\
\hline Conscientiousness & $3.19(0.43)$ & $2.94(0.48)$ & 0.107 & $\mathrm{~T}=-1.65$ \\
\hline \multicolumn{5}{|l|}{ SPREUK-15 $\alpha=0.796$} \\
\hline Religious/spiritual desires & $29.50(32.44)$ & $26.75(28.39)$ & 0.925 & $\mathrm{Z}=-0.11$ \\
\hline Trust & $50.50(34.82)$ & $50.00(26.25)$ & 0.959 & $\mathrm{~T}=0.05$ \\
\hline Reflection & $53.75(28.64)$ & $54.56(28.08)$ & 0.928 & $\mathrm{~T}=-0.09$ \\
\hline
\end{tabular}

For interpretation of values, see Methods section. $\alpha=$ Cronbach's alpha. * Separate $\alpha$ for positive affect and negative affect due to 2 scales.

the entire sample with no statistically significant differences between the groups (LP: mean 66.0, SD 9.62 vs. C: mean 65.3, SD 10.17; $p=0.824$ ) due to matching. As presented in Table 1, in the LP group, more women had different educational level regarding school graduation, and the number of women not believing in any religion was lower in this group ( 15 vs. $25 \%$ in C; $p=0.370$ ). These differences were not statistically significant. There was also not statistically significant difference regarding number of children (LP: mean 1.4, SD 1.14 vs. C: mean $1.35, \mathrm{SD} 1.26 ; p=0.824$ ) and relationship status $(p=0.80)$.

\section{Positive and Negative Affect Schedule (Table 2)}

The measured level of positive affectivity was statistically significantly higher in the LP (mean 37.10 , SD 5.07 vs. C: mean 32.00 , SD 7.78; $p=0.019$ ). In contrast, regarding the negative affect values, both groups had a similar level of negative affectivity (LP: mean 18.05 , SD 7.70 vs. C: mean 19.85 , SD 7.35; $p=0.314$ ).

\section{Illness Perception Questionnaire- $R$ (Table 2)}

The values of the item "timeline" differed significantly between the LP and the C groups (LP: mean 14.80, SD
4.89 vs. C: mean 12.00 , SD $4.72 ; p=0.038)$. So, patients with late presentation think their illness will last for a long time or is likely to be permanent.

Regarding causes of the disease, patients with late presentation seemed to have a less accurate understanding of their illness (coherence; LP: mean 14.20, SD 5.79 vs. C: mean 16.30, SD 3.77; $p=0.182$ ), even if the difference was not significant.

Negative emotional response tended to be lower in the LP (mean 14.65, SD 6.61) than in the C group (mean 17.75 , SD $4.89 ; p=0.10)$.

No trend was detectable regarding consequences (LP: mean 13.70 , SD 4.18 vs. C: mean 13.85, SD $4.85 ; p=$ 0.917), personal control (LP: mean 15.60, SD 2.92 vs. C: mean 14.30, SD 3.98; $p=0.247$ ), control by treatment (LP: mean 16.40 vs. C: mean $16.70 ; p=0.820$ ), and cyclic appearance (LP: mean 9.60 vs. C: mean 9.30; $p=0.182$ ).

\section{State-Trait Anxiety Inventory (Table 2)}

Regarding the state scale, no statistically significant difference between both groups was detectable (LP: mean 49.05, SD 17.3 vs. C: mean 50.7, SD 13.26; $p=0.737$ ), meaning that both groups did not differ regarding their state anxiety. 
In contrast, in the trait scale, the mean of the LP (34.55, SD 12.19) was lower than the mean of the C group (37.70, SD 10.23). Although the difference was not significant $(p=0.174)$, this trend suggests that patients with late presentation show less trait anxiety.

\section{NEO Five-Factor Inventory (Table 2)}

The LP tended to show higher values regarding conscientiousness than the C group (LP: mean 3.19, SD 0.43 vs. C: mean $2.95, \mathrm{SD} 0.48$ ) even if the difference was not significant $(p=0.107)$.

No differences between the LP and the $\mathrm{C}$ groups were detectable regarding neuroticism (LP: mean 1.50, SD 0.99 vs. C: mean 1.51, SD 0.72; $p=0.978$ ), extraversion (LP: mean 2.16 , SD 0.55 vs. C: mean 2.35 , SD $0.68 ; p=0.431$ ), openness to experience (LP: mean 2.32, SD 0.59 vs. C: mean 2.39, SD 0.46; $p=0.668$ ), and agreeableness (LP: mean 2.85 , SD 0.42 vs. C: mean 2.96 , SD $0.43 ; p=0.353$ ).

\section{Spiritual and Religious Attitudes in Dealing with \\ Illness-15 (Table 2)}

Comparing spiritual and religious attitudes in both groups, the absolute number of patients in the LP group searching for religious or spiritual sources was higher than in the $\mathrm{C}$ group, but there was no significance (LP: mean 29.5, SD 32.44 vs. C: mean 26.75, SD 29.40; $p=$ 0.925). Neither this finding nor the differences in the scales "trust" (LP: mean 50.50, SD 34.82 vs. C: mean 50.00, SD 26.25; $p=0.959$ ) and "reflection" (LP: mean 53.75, SD 28.64 vs. C: mean 54.56 , SD 28.08 ; $p=0.928)$ were statistically significant.

\section{Discussion}

As late presentation with $\mathrm{BC}$ is associated with poor survival, many studies were performed to find personal or structural reasons for this behavior [25]. This study aimed to analyze personal characteristics and attitudes of patients with delay in presentation.

Regarding religious and spiritual attitudes, previously performed studies could not detect any significant associations with the time of first presentation for BC [26]. In our cohort, patients with late presentation tended to have more desire for spiritual and religious sources, and there were fewer patients with late presentation not believing in any religion.

More patients with late presentation assumed that their disease would last for a long time compared to the $\mathrm{C}$ group. In case of $\mathrm{T} 4$ tumors, the risk for involved lymph nodes or distant metastasis is higher, which then leads to more extensive therapy with surgery, radiation, and/or systemic therapy [27]. Due to its systemic nature, advanced breast carcinoma is often declared as a chronic disease [28]. Even though patients who present late are aware of the chronicity of their disease, it is not clear if they would have also suspected $\mathrm{BC}$ to be longer lasting if they had presented earlier with a potentially good opportunity of shorter treatment and cure.

In our study, patients with late presentation had less understanding of their disease in general. Other studies showed that insufficient explanations could be a psychological reaction to save mental health, or that the attempt to explain reasons for $\mathrm{BC}$ is related to a lower educational level [15]. A low educational level has also been correlated with advanced T-stage $[29,30]$. We could not confirm this finding, as in our study patients with delayed presentation rather had a higher educational level than the participants in the $\mathrm{C}$ group. Nevertheless, this difference was not significant, and we did not ask for advanced education (e.g., university degrees), so this topic may need to be further investigated.

Regarding "anxiousness" as a trait, patients with early presentation at first diagnosis showed higher levels, which may cause a higher need for safety and professional medical care. As a consequence, they may see their physician more often and participate more frequently in screening programs, which may then contribute to an earlier diagnosis in this patient group [31]. In contrast, other studies postulated that the state "anxiety" led to a late presentation, also in patients with other malignant diseases [32], but this effect was not detectable in our study. It is well known that cancer patients in general have higher levels of negative emotional response to the illness like anxiety and depression [33]. In our study, however, we could not verify a difference in negative emotional response between late and early presenters. Patients with locally advanced $\mathrm{BC}$ at the initial diagnosis had relatively more positive feelings and a statistically significantly higher positive affect compared to the $\mathrm{C}$ group, which may be related to lower trait anxiety. Nevertheless, cancer patients in general tend to have a higher probability of negative emotional states compared to the healthy population, because they are afraid of the consequences of the diagnosis $[12,13,34]$.

LP showed more conscientiousness compared to BC patients presenting early. As this feature in the context of the NEO-FFI is defined as responsibility, sense of duty, self-discipline, and reliability, its assessment is often related to performance [22]. In contrast, health is not as well measurable. Additionally, in the western world, breasts are symbols of maternity and beauty [35]. Both items can be connected to self-discipline and responsibility and are better measurable by their visibility than health. So, patients may fear being perceived as unconscientious and may therefore present even later.

A limitation of this study is the small sample size. However, the study was planned as a pilot project focusing on patients with locally advanced and even exulcer- 
ated $\mathrm{BC}$ at primary diagnosis. Given the fact that this patient group is quite rare in breast centers and is often not willing to participate in a clinical study, acquiring a higher number of patients was not considered feasible. Consequently, the statistical analysis and conclusions are more of a descriptive than a quantitative nature.

In summary, patients with locally advanced $\mathrm{BC}$ at initial diagnosis were found to have significantly higher positive affectivity and more frequently perceived their illness as long-lasting or permanent. Other personal characteristics, such as educational level, spirituality, explanation of the illness, trait scale, and conscientiousness, also differed numerically but not statistically between early and late presenting patients. In summary, statistically significant differences between the groups justified acceptance of the alternative hypothesis for the parameters "positive affect" and "timeline," whereas no such differences could be shown and, thus, the null hypothesis was maintained for all other parameters under investigation. However, the findings of this pilot project warrant further investigations to identify characteristics and motives of patients with late presentation for $\mathrm{BC}$. The understanding of patients' reasons for not visiting a physician at first symptoms may help to identify the patient group that does not tend to see a physician early. Identifying this patient group might help to establish specific screening and health education programs to contact this hardly reachable patient group. By improving the awareness of this patient group and by simplifying the approach to a breast specialist, this might lead to an earlier contact if symptoms appear. If we were thereby able to provide this patient group with an earlier diagnosis in case of $\mathrm{BC}$, this could help to improve their therapy and probably their outcome.

\section{Acknowledgements}

We thank Claire Drotleff for her support. We thank Michelle Etheridge, M.A. Interpreting and Translating, for professional language editing.

\section{Statement of Ethics}

All procedures performed in studies involving human participants were in accordance with the ethical standards of the LMU ethics committee (reference number 322-13) and with the 1964 Helsinki Declaration and its later amendments or comparable ethical standards. This article does not contain any studies with animals performed by any of the authors. Informed consent was obtained from all individual participants included in the study.

\section{Conflict of Interest Statement}

Thomas Kolben holds stock of Roche AG and has a relative employed at Roche AG. Theresa M. Kolben is employed at Roche AG and holds stock of Roche AG. Tom Degenhardt has received grants from Pfizer, Roche, GSM, and Daiichi Sankyo. Rachel Wuerstlein has received research and travel support as well as honoraria from Roche, Celgene, AstraZeneca, MSD, Lilly, and Pfizer Oncology. Sven Mahner has received research and travel support and honoraria from AstraZeneca, Bayer, Boehringer Ingelheim, Jenapharm, GSK, Janssen-Cilag, Medac, MSD, Pharmamar, Roche, Tesaro, and Teva. Anna Hester has received research grants from the "Walter Schulz" foundation and travel support from Roche and Pfizer Oncology. All other authors declare that they have no conflicts of interest.

\section{Funding Sources}

The study received no funding.

\section{Author Contributions}

Thomas Kolben designed the experiment and wrote the manuscript. Susanne Beyer analyzed and interpreted the data and wrote the manuscript. Sanaz Ghasemi performed the experiment and analyzed the data. All authors analyzed and interpreted the results and read and approved the manuscript. Anna Hester read and revised the manuscript.

\section{References}

1 Jemal A, Bray F, Center MM, Ferlay J, Ward E, Forman D. Global cancer statistics. CA Cancer J Clin. 2011 Mar-Apr;61(2):69-90.

2 Rosen PP, Groshen S, Kinne DW, Norton L. Factors influencing prognosis in node-negative breast carcinoma: analysis of 767 T1N0M0/T2N0M0 patients with long-term follow-up. J Clin Oncol. 1993 Nov;11(11): 2090-100.

3 Newman LA. Epidemiology of locally advanced breast cancer. Semin Radiat Oncol. 2009 Oct;19(4):195-203.

4 Brito RA, Valero V, Buzdar AU, Booser DJ, Ames F, Strom E, et al. Long-term results of combined-modality therapy for locally ad- vanced breast cancer with ipsilateral supraclavicular metastases: The University of Texas M.D. Anderson Cancer Center experience. J Clin Oncol. $2001 \mathrm{Feb} ; 19(3): 628-33$.

5 Scholl SM, Fourquet A, Asselain B, Pierga JY, Vilcoq JR, Durand JC, et al. Neoadjuvant versus adjuvant chemotherapy in premenopausal patients with tumours considered too large for breast conserving surgery: preliminary results of a randomised trial: S6. Eur J Cancer. 1994;30A(5):645-52.

6 Giordano SH. Update on locally advanced breast cancer. Oncologist. 2003;8(6):521-30.

7 Bauerfeind I, editor. Mammakarzinome. Empfehlungen zur Diagnostik, Therapie und
Nachsorge. Tumorzentrum München. München: W. Zuckschwerdt Verlag; 2017.

8 Anderson WF, Chu KC, Chang S. Inflammatory breast carcinoma and noninflammatory locally advanced breast carcinoma: distinct clinicopathologic entities? J Clin Oncol. 2003 Jun;21(12):2254-9.

9 Robert Koch-Institut. Beiträge zur Gesundheitsberichterstattung des Bundes. Krebs in Deutschland 2011/2012. Eine gemeinsame Veröffentlichung des Robert Koch-Instituts und der Gesellschaft der epidemiologischen Krebsregister in Deutschland e.V. 10. Ausgabe. Berlin: Robert KochInstitut; 2015. 
10 Ramirez AJ, Westcombe AM, Burgess CC, Sutton S, Littlejohns P, Richards MA. Factors predicting delayed presentation of symptomatic breast cancer: a systematic review. Lancet. 1999 Apr;353(9159):1127-31.

11 Grunfeld EA, Ramirez AJ, Hunter MS, Richards MA. Women's knowledge and beliefs regarding breast cancer. Br J Cancer. 2002 May; 86(9):1373-8

12 Hunter MS, Grunfeld EA, Ramirez AJ. Helpseeking intentions for breast-cancer symptoms: a comparison of the self-regulation model and the theory of planned behaviour. Br J Health Psychol. 2003 Sep;8(Pt 3):319-33.

13 Burgess C, Hunter MS, Ramirez AJ. A qualitative study of delay among women reporting symptoms of breast cancer. Br J Gen Pract. 2001 Dec;51(473):967-71.

14 Bish A, Ramirez A, Burgess C, Hunter M. Understanding why women delay in seeking help for breast cancer symptoms. J Psychosom Res. 2005 Apr;58(4):321-6.

15 Montagna G, Schneeberger AR, Rossi L, Bianchi Micheli G, Meani F, Imperiali M, et al. Can we make a portrait of women with inoperable locally advanced breast cancer? Breast. 2017 Jun;33:83-90.

16 Krohne HW, Egloff B, Kohlmann CW, Tausch A. Untersuchungen mit einer deutschen Version der "positive and negative affect schedule" (PANAS). Diagnostica. 1996; 42:139-56.

17 Watson D, Clark LA, Tellegen A. Development and validation of brief measures of positive and negative affect: the PANAS scales. J Pers Soc Psychol. 1988 Jun;54(6):1063-70.

18 Moss-Morris R, Weinman J, Petrie K, Horne $\mathrm{R}$, Cameron L, Buick D. The Revised Illness Perception Questionnaire (IPQ-R). Psychol Health. 2002;17(1):1-16.
19 Glattacker M, Bengel J, Jäckel WH. Die deutschsprachige Version des Illness Perception Questionnaire-Revised: Psychometrische Evaluation an Patienten mit chronisch somatischen Erkrankungen. Z Gesundh psychol. 2009;17(4):158-69.

20 Laux L, Glanzmann P, Schaffner P, Spielberger CD. Das State-Trait-Angstinventar. Theoretische Grundlagen und Handanweisung. Göttingen: Hogrefe; 1981.

21 Spielberger C, Gorsuch RL, Lushene RE. Manual for the State-Trait Anxiety Inventory. Palo Alto (Ca.): Consulting Psychologists Press; 1970.

22 Borkenau P, Ostendorf F. NEO-Fünf-Faktoren Inventar (NEO-FFI) nach Costa und McCrae. Göttingen: Hogrefe; 1993. p. 5-10, 27-28.

23 Büssing A. Spirituality as a Resource to Rely on in Chronic Illness: The SpREUK Questionnaire. Religions (Basel). 2010;1(1):9-17.

24 Büssing A, Ostermann T, Matthiessen PF. Role of religion and spirituality in medical patients: confirmatory results with the SpREUK questionnaire. Health Qual Life Outcomes. 2005 Feb; 3: 10

25 Richards MA, Westcombe AM, Love SB, Littlejohns P, Ramirez AJ. Influence of delay on survival in patients with breast cancer: a systematic review. Lancet. 1999 Apr;353(9159): 1119-26.

26 Gullatte MM, Brawley O, Kinney A, Powe B, Mooney K. Religiosity, spirituality, and cancer fatalism beliefs on delay in breast cancer diagnosis in African American women. J Relig Health. 2010 Mar;49(1):62-72.

27 Fitzal F, Riedl O, Wutzl L, Draxler W, Rudas $\mathrm{M}$, Pluschnig $\mathrm{U}$, et al. Breast-conserving surgery for T3/T4 breast cancer: an analysis of 196 patients. Breast Cancer Res Treat. 2007 May;103(1):45-52.
28 Di Lascio S, Pagani O. Is it time to address survivorship in advanced breast cancer? A review article. Breast. 2017 Feb;31:167-72.

29 Liu Y, Zhang J, Huang R, Feng WL, Kong YN, $\mathrm{Xu} \mathrm{F}$, et al. Influence of occupation and education level on breast cancer stage at diagnosis, and treatment options in China: A nationwide, multicenter 10-year epidemiological study. Medicine (Baltimore). 2017 Apr; 96(15):e6641.

30 Friedman LC, Kalidas M, Elledge R, Dulay MF, Romero C, Chang J, et al. Medical and psychosocial predictors of delay in seeking medical consultation for breast symptoms in women in a public sector setting. J Behav Med. 2006 Aug;29(4):327-34.

31 Hay JL, McCaul KD, Magnan RE. Does worry about breast cancer predict screening behaviors? A meta-analysis of the prospective evidence. Prev Med. 2006 Jun;42(6):401-8.

32 Nosarti C, Crayford T, Roberts JV, Elias E, McKenzie K, David AS. Delay in presentation of symptomatic referrals to a breast clinic: patient and system factors. Br J Cancer. 2000 Feb;82(3):742-8.

33 Markovitz SE, Schrooten W, Arntz A, Peters ML. Resilience as a predictor for emotional response to the diagnosis and surgery in breast cancer patients. Psychooncology. 2015 Dec;24(12):1639-45.

34 Voogt E, van der Heide A, van Leeuwen AF, Visser AP, Cleiren MP, Passchier J, et al. Positive and negative affect after diagnosis of advanced cancer. Psychooncology. 2005 Apr; 14(4):262-73.

35 Potrata B. Cultures, subcultures and late presentation with breast cancer. Asian Pac J Cancer Prev. 2011;12(6):1609-13. 